\title{
An effective tumor vaccine optimized for costimulation via bispecific and trispecific fusion proteins
}

\author{
MAXIMILIAN AIGNER, MARKUS JANKE, MARIA LULEI, PHILIPP BECKHOVE, \\ PHILIPPE FOURNIER and VOLKER SCHIRRMACHER \\ German Cancer Research Center, Division of Cellular Immunology, Heidelberg, Germany
}

Received November 5, 2007; Accepted December 27, 2007

\begin{abstract}
T cell costimulation has great therapeutic potential if it can be optimized and controlled. To achieve this, we engineered $\mathrm{T}$ cell-activating fusion proteins and immunocytokines that specifically attach to viral antigens of a virusinfected tumor vaccine. We employed the avian Newcastle Disease Virus because this agent is highly efficient for human tumor cell infection, and leads to introduction of viral hemagglutinin-neuraminidase (HN) molecules at the tumor cell surface. Here, we demonstrated the strong potentiation of the $\mathrm{T}$ cell stimulatory activity of such a vaccine upon attachment of bispecific or trispecific fusion proteins which bind with one arm to viral HN molecules of the vaccine, and with the other arm either to CD3 (signal 1), to CD28 (costimulatory signal $2 \mathrm{a}$ ), or to interleukin-2 receptor (costimulatory signal $2 \mathrm{~b}$ ) on $\mathrm{T}$ cells. A vaccine with a combination of all three signals triggered the strongest activation of naïve human $\mathrm{T}$ cells, thereby inducing the most durable bystander antitumor activity in vitro. Adoptive transfer of such polyclonally activated cells into immunodeficient mice bearing human breast carcinoma caused tumor regression. Furthermore, tumor-reactive memory $\mathrm{T}$ cells from draining lymph nodes of carcinoma patients could be efficiently reactivated in a short-term ELISpot assay using an autologous tumor vaccine with optimized signals 1 and 2, but not with a similarly modified vaccine from an unrelated tumor cell line. Our data describe new bioactive molecules which in combination with an established virus-modified tumor vaccine greatly augments the antitumor activity of T cells from healthy donors and cancer patients.
\end{abstract}

\section{Introduction}

The strength of T cell stimulation is determined by numerous parameters including i) the concentration of major histocompatibility complex-restricted antigen on the surface

Correspondence to: Professor Volker Schirrmacher, German Cancer Research Center (DKFZ), Division of Cellular Immunology (D010), Im Neuenheimer Feld 280, 69120 Heidelberg, Germany

E-mail: v.schirrmacher@dkfz-heidelberg.de

Key words: fusion protein, immunocytokine, costimulation, cancer vaccination of antigen-presenting cells (APCs) such as dendritic cells (DCs) and its affinity for the T cell receptor (TCR; determining the rate of TCR triggering) $(1,2)$, ii) the presence or absence of costimulation (regulating the extent of signal amplification) $(3,4)$, such as costimulation via CD28 which is the most prominent costimulatory receptor on $\mathrm{T}$ cells $(5,6)$, and iii) the duration of the interactions between $\mathrm{T}$ cells and DCs (setting the duration of the signalling process) $(7,8)$. A low-strength stimulation which may occur with tumor cells can have a negative effect leading to T cell unresponsiveness (anergy) (9), or apoptosis $(10,11)$. However, CD28 engagement drives interleukin-2 (IL-2) production $(12,13)$, a cytokine pivotal for T cell growth, survival and cytotoxicity (14).

We have already reported on three recombinant, monomeric single chain Fv (scFv) fusion proteins (15-17). These specially designed molecules provide $\mathrm{T}$ cell activation signals by interacting either with the TCR-associated CD3 complex [signal 1, mediated by the bispecific (bs) fusion protein bsHN-CD3], or with the costimulatory molecule CD28 (signal 2a, mediated by bsHN-CD28), or with the IL-2 receptor (signal $2 \mathrm{~b}$, mediated by bsHN-IL-2). The trispecific (ts) IL-2 immunocytokine/scFv fusion protein tsHN-IL-2CD28 described for the first time in this study combines both costimulatory activities (signals $2 \mathrm{a}$ and $2 \mathrm{~b}$ ). Such costimulatory signals as well as additional signal 1 may be particularly required in cancer patients whose $\mathrm{T}$ cells exhibit a high degree of unresponsiveness to stimulation via tumor-associated antigens (TAAs).

Instead of targeting TAAs which are often heterogeneously expressed within a tumor and between different tumors, our engineered fusion proteins and IL-2 immunocytokines bind to the viral antigen (VA) hemagglutininneuraminidase (HN). This molecule becomes expressed on tumor cells upon infection with the avian paramyxovirus Newcastle Disease Virus (NDV) (18). The advantages of this concept are i) that NDV has tumor-selective replication properties (19), ii) that VAs can serve as universal anchor molecules for these fusion proteins and/or immunocytokines, and iii) that NDV provides danger signals thus activating additional innate antitumor immune mechanisms. Human tumor cell infection by NDV is an efficient and safe way to produce an autologous tumor vaccine (first generation ATVNDV) with pleiotropic immunostimulatory properties (20). Promising results have already been reported from several clinical phase II trials, including breast cancer $(21,22)$, colon 
carcinoma $(23,24)$, head and neck squamous cell carcinoma (HNSCC) (25), and glioblastoma (26).

Here we describe how, in a stepwise procedure, such an ATV-NDV can be optimized for costimulation with HNspecific $\mathrm{scFv}$ fusion proteins and immunocytokines in order to potentiate $\mathrm{T}$ cell responses by providing a maximum of activating signals. The results obtained from in vitro tumor neutralization experiments, ELISpot assays and from in vivo tumor xenotransplant rejection experiments expand our first results and reveal that this second generation tumor vaccine is more potent than the first. It may be applicable to the treatment of virtually any type of human cancer, provided that the cancer cells are susceptible to infection by NDV, a prerequisite for further modification with the virus-specific fusion proteins.

\section{Materials and methods}

Mice, cell lines, antibodies for flow cytometry, and reagents. Non-obese diabetic/severe combined immunodeficient (NOD/SCID) mice, 6-8 weeks of age, were purchased (Charles River Laboratories, Sulzfeld, Germany). All cell lines were obtained from the tumor cell bank of the German Cancer Research Center (DKFZ). Cell culture media were supplemented with $2 \mathrm{mM}$ L-glutamine, $10 \mathrm{mM}$ HEPES, $100 \mathrm{U} / \mathrm{ml}$ penicillin and $100 \mu \mathrm{g} / \mathrm{ml}$ streptomycin (all purchased from Gibco Invitrogen, Karlsruhe, Germany). The human breast carcinoma cell line MCF-7 was cultured in DMEM medium with $10 \%$ fetal calf serum (FCS; Gibco Invitrogen). The human promonocytic lymphoma cell line U937, as well as the murine fibroblast line Ltk.wt and its HN cDNA (Ltk.HN) transfectant A2 (27) were maintained in RPMI-1640 medium with $10 \%$ FCS. The human T cell lymphoma line CTLL was grown in Iscove's medium containing $10 \%$ FCS and $25 \mathrm{U} / \mathrm{ml}$ recombinant human IL-2 (Chiron Therapeutic, Emeryville, CA, USA). For flow cytometry, mAbs against His $_{6}$-tag and E-tag were obtained from Dianova (Hamburg, Germany) and Amersham Biosciences (Freiburg, Germany), respectively. PE-labelled goat $\mathrm{F}\left(\mathrm{ab}^{\prime}\right)_{2}$ anti-mouse $\mathrm{IgG}$ was from Southern Biotech (Birmingham, AL, USA). Anti-NDV HN mAb (HN.B) was produced by a murine hybridoma cell line (kindly provided by Dr R.M. Iorio, University of Massachusetts, Medical School, MA, USA). Anti-human CD25-FITC (M-A251), antihuman CD45RO-PE (UCHL1), and anti-human CD107a-PE (H4A3) were purchased from BD Pharmingen (Heidelberg, Germany); anti-human CD8-APC (3B5) was from Caltag Laboratories (Hamburg, Germany). Human IgG was from Baxter (Unterschleissheim, Germany). Propidium iodide and staphylococcal enterotoxin B (SEB) were purchased from Sigma-Aldrich (Schnelldorf, Germany).

Patients and patient-derived tumor cultures and T cells. Tumor tissue samples from primary tumors of 4 patients with pathologically confirmed HNSCC [UICC stages II-IV; oropharynx $n=1$, hypopharynx $n=1$, larynx $n=1$, CUP (cancer with unknown primary) $n=1$; median age at diagnosis 68 years (range 59-74 years)] were taken from the specimens immediately after surgical removal at the Department of Head and Neck Surgery at the University of Heidelberg.
Informed consent from the patients was obtained prior to surgery. Tumor cell cultures were established and maintained as described previously (25). Histologically metastasis-free draining lymph nodes were also removed from the same patients. They served as a source of autologous $\mathrm{T}$ cells. Briefly, lymph nodes were mechanically dissociated in medium and the resulting suspension was passed through a $40-\mu \mathrm{m}$ cell strainer (BD Falcon, Heidelberg, Germany). T cells were negatively isolated using magnetic beads coated with antiCD15, anti-CD19 and anti-CD56 mAbs (all from Dynal, Hamburg, Germany) and cryopreserved until used.

Construction and production of recombinant fusion proteins. The plasmids pERdhfr $(\alpha \mathrm{HN}-\alpha \mathrm{CD} 3)(\# 242)$ and pERdhfr $(\alpha \mathrm{HN}-$ aCD28) (\#290) (15) encoding the bispecific fusion proteins bsHN-CD3 and bsHN-CD28, respectively, as well as the plasmid pERdhfr( $\alpha \mathrm{HN}-\mathrm{IL}-2)$ (\#356) encoding the immunocytokine bsHN-IL-2 (17) have been described. The plasmid pERdhfr( $\alpha$ HN-IL-2- $\alpha$ CD28) (\#716) encoding the trispecific fusion protein/immunocytokine tsHN-IL-2-CD28 was obtained by cloning the human IL-2 cDNA (derived from plasmid pFc54.7; ATCC, Rockville, MD, USA) between the anti-HN and anti-CD28 scFv portions of plasmid $\mathrm{pERdhfr}(\alpha \mathrm{HN}-\alpha \mathrm{CD} 28)$. The fusion proteins were produced and purified by affinity chromatography as described (15). The protein concentrations were determined with the CBProtein Assay ${ }^{\mathrm{TM}}$ Reagent (Calbiochem, Schwalbach, Germany) and using bovine serum albumin (BSA) as reference protein. In order to be able to compare the fusion proteins with each other, they were separately titrated for their binding to Ltk.HN cells using FACS analysis. An arbitrary HN activity of $10,000 \mathrm{U} / \mathrm{ml}$ was attributed to a protein dilution which stained $50 \%$ of the Ltk.HN cells. The IL-2 activity of the fusion proteins was assessed using the IL-2-dependent cell line CTLL. A summary of the protein characteristics is provided in Table I. Their binding specificities to NDVinfected MCF-7 tumor vaccine cells and activated human $\mathrm{T}$ cells are outlined in Fig. 1.

$N D V$. For virus infection, the avirulent, non-lytic NDV strains Ulster and LaSota were used. Origin, maintenance, purification, and quantitation have been described (20). Unless otherwise noted, NDV Ulster was used throughout the experiments.

Isolation of peripheral blood mononuclear cells (PBMC) and PBMC subsets. Human PBMC were isolated via FicollPaque (Amersham Biosciences) centrifugation from buffy coats or from fresh heparinized blood of healthy donors. Natural killer (NK) cell, total T cell, CD4 ${ }^{+} \mathrm{T}$ cell and $\mathrm{CD} 8^{+}$ $\mathrm{T}$ cell subsets were magnetically purified from PBMC with the use of the corresponding Dynal Negative Isolation Kit (Hamburg, Germany). Naïve T cells were obtained by adding $1 \mu \mathrm{g}$ anti-CD45RO mAb per $10^{7}$ cells (UCHL1; BD Pharmingen, Heidelberg, Germany) to the antibody cocktail of the $\mathrm{T}$ Cell Negative Isolation Kit to additionally remove memory T cells. Monocytes were enriched via adherence to a plastic surface. Briefly, PBMC were incubated for $2 \mathrm{~h}$ at $37^{\circ} \mathrm{C}$ in cell culture flasks. Then, the supernatant was removed (nonadherent PBMC subset) and the remaining attached cells 
Table I. Summary of the characteristics of the purified fusion proteins. ${ }^{\mathrm{a}}$

\begin{tabular}{llccc}
\hline Plasmid reference no. & Protein structure & Protein amount $(\mu \mathrm{g} / \mathrm{ml})$ & HN activity $(\mathrm{U} / \mathrm{ml})$ & IL-2 activity (U/ml) \\
\hline 242 & bsHN-CD3 & 27.0 & n.d. & 0.0 \\
290 & bsHN-CD28 & 25.0 & $5.1 \times 10^{5}$ & 0.0 \\
716 G10 & tsHN-IL-2-CD28 & 49.6 & $2.0 \times 10^{5}$ & $1.6 \times 10^{6}$ \\
356 & bsHN-IL-2 & 103.3 & $2.0 \times 10^{5}$ & $1.4 \times 10^{6}$ \\
\hline
\end{tabular}

aEach fusion protein (plasmid reference no. and protein structure are provided) is characterized by its protein concentration, its HN activity, and its IL-2 activity (determined as described in Materials and methods). n.d, not determined.

A
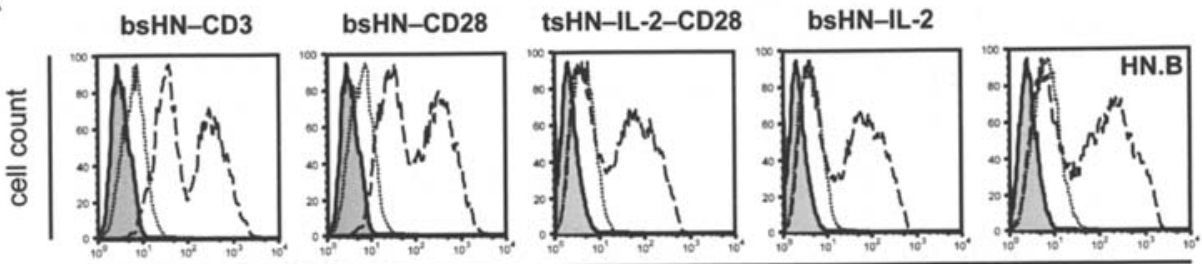

$\mathrm{HN}$

B

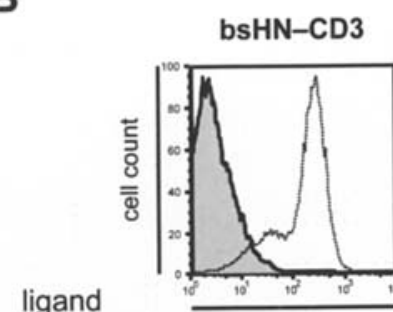

binding to:

CD3

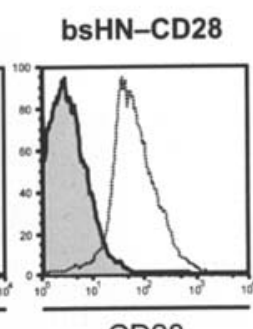

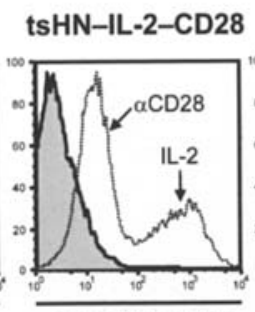

CD28 \& IL-2R

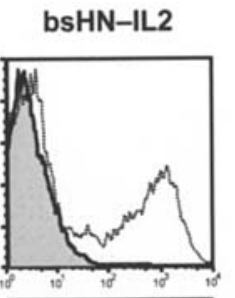

$\mathrm{IL}-2 \mathrm{R}$

Figure 1. Binding specificities of the purified fusion proteins to NDV-infected MCF-7 breast carcinoma cells (A) and preactivated human T cells (B). (A) Irradiated MCF-7 cells were infected with NDV and the fusion proteins were bound to the cells for 30 min on ice. The cells were washed and the proteins were detected with anti-His ${ }_{6}$-tag (for all except bsHN-CD28) or anti-E-tag (for bsHN-CD28) mAbs, followed by PE-labelled goat F(ab') ${ }_{2}$ anti-mouse antibody. Finally, the cells were analyzed by FACS. In the histogram overlays, dotted and dashed lines reflect the binding of the fusion proteins after $1 \mathrm{~h}$ (virus adsorption to the tumor cell membrane) and $24 \mathrm{~h}$ (virus replication) of virus infection, respectively. The NDV HN-specific mAb HN.B served as a positive control. (B) Purified T cells (TCs) were preactivated for $48 \mathrm{~h}$ by coincubation with autologous dendritic cells (DCs), generated as described (28), in the presence of SEB $(1 \mu \mathrm{g} / \mathrm{ml})$ at a TC:DC ratio of 5:1. Fusion proteins were bound and detected as in (A). Gray histograms represent cells stained with secondary antibodies only (without fusion proteins: negative controls). IL-2R, IL-2 receptor.

were washed twice before they were detached by scraping (adherent PBMC subset).

Vaccine preparation. MCF-7 or Ltk.wt cells were $\gamma$-irradiated with 200 or 100 Gy (Gammacell 1000; Atomic Energy of Canada), respectively and then modified for $1 \mathrm{~h}$ at $37^{\circ} \mathrm{C}$ with 100 hemagglutination units (HU) NDV Ulster or LaSota per $10^{7}$ cells (VN: MCF-7-NDV or Ltk.wt-NDV), as described (20). In some cases, the HN-expressing Ltk.HN cells ( $\gamma$-irradiated with $100 \mathrm{~Gy}$ ) were used as stimulator cells as a vaccine surrogate.

$\left[{ }^{3} H\right]-T d R$ incorporation assay. $\gamma$-irradiated Ltk.wt or Ltk.HN cells were used as stimulator cells in 96-well microtiter plates $\left(10^{4}\right.$ per well). The indicated amounts of the fusion proteins and purified T cells $\left(10^{5}\right.$ per well) were added. After $48 \mathrm{~h}$ of incubation, the cells were pulsed with $\left[{ }^{3} \mathrm{H}\right]-\mathrm{TdR}$ as described (15), and mean cpm values were calculated from triplicate experiments.
Mixed lymphocyte tumor cell culture (MLTC). In 96-well microtiter plates, $10^{5}$ freshly isolated naïve human $\mathrm{T}$ cells from healthy donors were coincubated with $10^{4}$ stimulator cells (either Ltk.wt-NDV vaccine cells or $\gamma$-irradiated Ltk.HN cells). After the indicated duration of incubation in the presence or absence of fusion proteins, the cells were harvested, washed twice, and either used in a tumor neutralization assay (described below) or stained for FACS analysis.

CFSE-based proliferation measurement of naïve T cells. Purified naïve human T cells were labelled with $0.2 \mu \mathrm{M}$ of the live cell dye CFSE (Molecular Probes, Leiden, The Netherlands) for $10 \mathrm{~min}$ at room temperature. The reaction was quenched by washing the cells in culture medium containing $5 \%$ FCS. Cells $\left(10^{5}\right.$ per well $)$ were activated in an MLTC in the presence of the indicated combinations of the fusion proteins, using Ltk.wt-NDV or MCF-7-NDV as vaccine cells. At the end of the MLTC, T cells were harvested and analyzed by flow cytometry. Dividing cells (and the numbers 
of cell divisions) were determined by comparing the CFSE dilution with naïve $\mathrm{T}$ cells stimulated by vaccine cells only.

Tumor neutralization assay (TNA). The assay system was adjusted from Haas et al (16). The experimental tests were performed in 96-well microtiter plates (in triplicates). For effector cell passages, the setup was scaled up to a 6-well TNA system (in duplicates). Briefly, using 96- or 6-well plates, $3 \times 10^{3}$ or $5 \times 10^{4}$ live MCF-7 tumor target cells, respectively, were seeded and incubated for $4 \mathrm{~h}$ until they became adherent. Effector cells (derived from healthy donors) were either freshly isolated, non-activated total PBMC (Fig. 4), purified subsets from PBMC (Figs. 4A and $5 \mathrm{~B}$ ), or naïve human $\mathrm{T}$ cells that had been preactivated in an MLTC using Ltk.HN as a vaccine surrogate (Fig. 5A); in the first two cases, the effector cells were added to the wells at an effector to target cell ratio of 5:1 (i.e. $1.5 \times 10^{4}$ cells per well). When using non-activated responder cells (Figs. 4 and $5 \mathrm{~B}), 10^{3}$ or $1.67 \times 10^{4} \mathrm{MCF}-7-\mathrm{NDV}$ vaccine cells were used for the 96- or 6-well TNA system, respectively. Subsequently, the fusion proteins were added at the indicated concentrations. Then, the plates were incubated until the tumor monolayer in the control wells became confluent (6-7 days for the first passage, and 3 days for the following passages or when MLTC-preactivated cells were used). Finally, the surviving tumor cells in the 96-well TNA test plates were quantified and the tumor growth inhibition was calculated from triplicates as described (16). For passages, the effector cells from the 6well plates were harvested, washed twice, and added onto fresh MCF-7 monolayer targets $\left(2.5 \times 10^{4}\right.$ or $4.2 \times 10^{5}$ cells per well for a 96- or 6-well TNA, respectively).

Interferon- $\gamma(I F N-\gamma)$ ELISpot. To determine systemic tumorreactive T cell immunity in HNSCC patients, we performed a short-term ELISpot (enzyme-linked immunospot) assay, as described (28). It was modified insofar as purified patientderived $\mathrm{T}$ cells isolated from draining lymph nodes were not stimulated with tumor antigen-presenting dendritic cells, but with autologous tumor vaccine cells loaded with fusion proteins. Briefly, tumor vaccine cells were prepared by $\gamma$-irradiation (200 Gy) and NDV LaSota infection (100 HU per $10^{7}$ cells), and loaded with the bispecific fusion proteins bsHN-CD3 (3 $\mu \mathrm{g}$ per $10^{6}$ cells) and/or bsHN-C28 (6 $\mu \mathrm{g}$ per $10^{6}$ cells). Loaded vaccine cells $\left(2 \times 10^{4}\right)$ were coincubated for $40 \mathrm{~h}$ with $2 \times 10^{5}$ autologous $\mathrm{T}$ cells in IP-ELISpot plates (Millipore, Molsheim, France) coated with an anti-IFN- $\gamma$ mAb (1-D1K; Mabtech, Hamburg, Germany) and analyzed for cytokine secretion according to the manufacturer's protocol. Spot-forming cells were quantified using an Axioplan 2 Imaging Microscope (Zeiss, Oberkochen, Germany) and the KS-ELISpot software (Zeiss Vision, Göttingen, Germany). All tests were performed in triplicates. The allogeneic promonocytic lymphoma cell line U937 was used as a specificity control instead of autologous tumor cells.

Assay for immunotherapeutic capacity in vivo. MCF-7 tumor cells $\left(10^{7}\right)$ were injected s.c. into NOD/SCID mice $(n=8$ per group). The mice were kept until the tumors reached a diameter of 6-8 $\mathrm{mm}$. Then, at intervals of 3 days (at days 1 , 4 , and 7), mice were treated thrice by an i.p. injection of $10^{7}$
PBMC from a healthy, HLA-A2-positive donor (thereby matching the HLA-A2-positive MCF-7 tumor cell line). The PBMC were preactivated ex vivo for 3 days either with MCF-7NDV tumor vaccine loaded with the bispecific fusion proteins bsHN-CD3 (10 $\mu \mathrm{g}$ per $10^{7}$ cells) and bsHN-CD28 (30 $\mu \mathrm{g}$ per $10^{7}$ cells) (full activation), or with MCF-7-NDV tumor vaccine only. A third group consisted of mice receiving i.p. the supernatant from fully activated PBMC. PBS-treated mice served as a negative control. Tumor growth was assessed over time at intervals of 6-14 days.

Immunohistochemistry. At the end of the therapy experiment, tumor tissue samples from treated mice were removed and shock-frozen in liquid nitrogen. To detect human lymphocyte infiltration, $5-\mu \mathrm{m}$ cryosections were cut and stained with murine anti-human mAbs against CD4, CD8, CD69 and CD45RO (all from Dako, Hamburg, Germany). Visualization was performed using a horseradish peroxidase-conjugated polyclonal goat anti-mouse immunoglobulin and 3-amino-9ethylcarbazole as substrate (TissueGnost AEC; Merck, Darmstadt, Germany). Sections were counterstained with hematoxylin to reveal histological structures.

Statistical analysis. Differences between two means were calculated in Excel software with the two-tailed Student's t-test. They were considered significant at a p-value $\leq 0.05$. For the in vivo experiment, analysis of variance (ANOVA) was applied. p-values from multiple testings were adjusted according to Bonferroni-Holm.

\section{Results}

$T$ cell costimulatory activity of anti-CD28- and IL-2containing fusion proteins. The two proteins bsHN-CD28 and tsHN-IL-2-CD28 were compared for costimulatory activity based on equal units of binding to viral HN. Costimulatory activity was tested in a $\mathrm{T}$ cell proliferation assay $\left(\left[{ }^{3} \mathrm{H}\right]-\mathrm{TdR}\right.$ incorporation) in which purified $\mathrm{T}$ cells from human peripheral blood were coincubated with $\gamma$-irradiated Ltk.HN cells in the presence of different concentrations of these proteins and of a suboptimal concentration of bsHN-CD3 (signal 1) (Fig. 2A). bsHN-CD28 (signal 2a; Fig. 2B) and tsHN-IL-2-CD28 (signal 2a plus 2b: 2a-2b; Fig. 2C) showed both costimulatory activity. There was no costimulatory effect with Ltk cells expressing no HN protein (Ltk.wt) for bsHN-CD28 (Fig. 2B) while tsHN-IL-2-CD28 caused a slight dose-dependent $\mathrm{T}$ cell proliferation (Fig. 2C) resulting from the IL-2 which can act both in a cell-bound and soluble form.

To exclude a contribution of memory $\mathrm{T}$ cells in the functional assay, we next studied the activation of purified naïve $T$ cells by a vaccine modified with the various fusion proteins. We labelled these highly pure naïve T cells, which also did not contain $\mathrm{T}$ regulatory cells (data not shown), with CFSE and quantified the numbers of cell divisions after 5 and 7 days by FACS analysis (Fig. 2D). While the majority of naïve $\mathrm{T}$ cells in the controls (stimulated with either suboptimal signal 1 alone, or signals $2 \mathrm{a}$ or $2 \mathrm{~b}$ alone, or signal $2 \mathrm{a}-2 \mathrm{~b}$ alone) underwent no divisions, the majority of cells that were provided with signal 1 in combination with either 

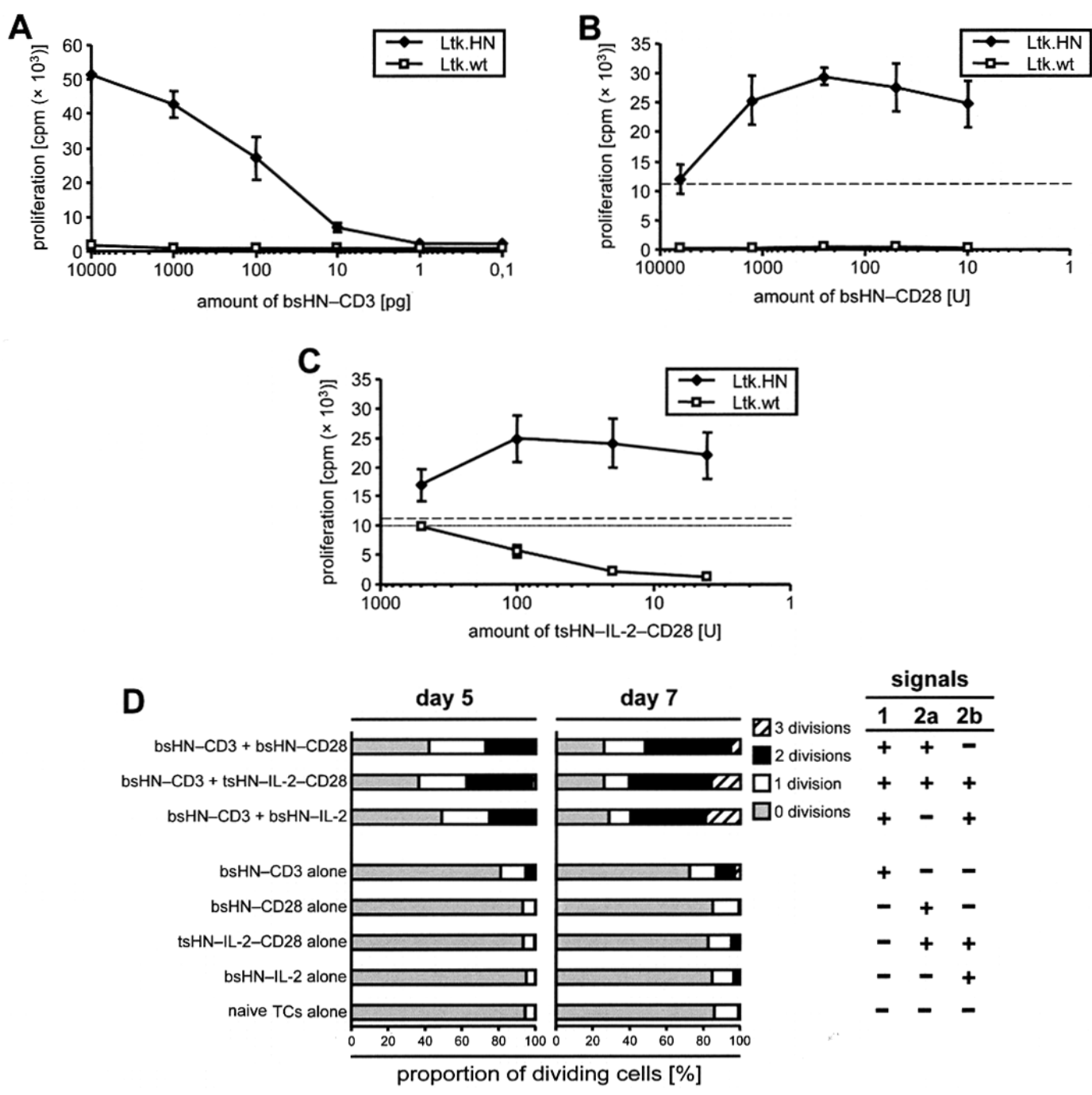

Figure 2. Induction of $\mathrm{T}$ cell proliferation by bispecific fusion proteins and IL-2 immunocytokines. (A) Titration of bsHN-CD3. For determination of a suboptimal dose of signal 1, purified T cells were stimulated for $48 \mathrm{~h}$ by $\gamma$-irradiated Ltk.HN or Ltk.wt cells (for control) in the presence of decreasing amounts of bsHN-CD3. Proliferation was assessed by $\left[{ }^{3} \mathrm{H}\right]-\mathrm{TdR}$ uptake, and the mean cpm of triplicate cultures \pm SD is shown. (B and C) Titration of bsHN-CD28 and tsHN-IL-2-CD28. For determination of the costimulatory capacity of the two fusion proteins, purified T cells were stimulated for 48 h by $\gamma$-irradiated Ltk.HN or Ltk.wt cells (for control), and a combination of a suboptimal dose of signal 1 (50 pg of bsHN-CD3, as derived from A; dashed lines) and decreasing amounts of costimulatory bsHN-CD28 (B) or tsHN-IL-2-CD28 (C), respectively, and proliferation was assessed as in A. Notice that costimulatory activity depended on specific binding to HN-expressing cells thus allowing cross-linking of $\mathrm{T}$ cells and aggregation of their respective receptors. The pure IL-2 effect of tsHN-IL-2-CD28 (in the absence of bsHN-CD3) is shown (C, dotted line). (D) Induction of proliferation in naïve T cells. Purified and CFSE-labelled naïve T cells (TCs) were activated for 5 (left) or 7 (right) days by Ltk.wt-NDV vaccine cells and a combination of a suboptimal dose of signal 1 (500 pg of bsHN-CD3) and 84 U/well of the costimulatory fusion proteins/immunocytokines bsHN-CD28, tsHN-IL-2-CD28 and bsHN-IL-2, respectively (upper part). For controls, naïve T cells were incubated with Ltk.wt-NDV vaccine cells either in the presence of either fusion protein alone, or without any construct (lower part). The CFSE signal intensities were compared with unstimulated cells (naïve T cells on top of Ltk.wt-NDV cells only) by FACS analysis. The cumulative proportions of cells having undergone no (gray), one (white), two (black), or three and more (hatched) divisions are shown.

signal $2 \mathrm{a}, 2 \mathrm{~b}$ or $2 \mathrm{a}-2 \mathrm{~b}$ underwent one, two or even three cell divisions. These quantitative data on $\mathrm{T}$ cell proliferation demonstrate i) that the vaccine-bound fusion proteins containing anti-CD28 scFv and/or IL-2 in combination with suboptimal signal 1 activated naïve $\mathrm{T}$ cells, and ii) that bsHN-IL-2 (signal 2b) was at least as costimulatory in this assay as bsHN-CD28 (signal 2a).

Induction of $T$ cell activation markers and effector function by NDV tumor vaccine presenting anti-CD28- and IL-2containing fusion proteins. $\mathrm{T}$ cell activation was further assessed by upregulation of activation markers and effector proteins. After coincubation of purified naïve T cells for 6 days with $\gamma$-irradiated Ltk.HN cells in the presence of the various fusion proteins, we measured the upregulation of $\mathrm{CD} 25$, the $\alpha$-chain of the IL-2 receptor, and CD45RO, a marker for the transition of naïve to memory cells (Fig. 3A). The classical combination of anti-CD3 in a suboptimal dose with antiCD28 at an optimal concentration (40.5 U) induced an upregulation of both markers in $20 \%$ of the T cells. Notably, the new immunocytokines containing IL-2 (signal 2b) induced a much stronger costimulatory effect (strictly depending on signal 1) so that at least twice as many $\mathrm{T}$ cells coexpressed CD25 and CD45RO. The superior costimulatory activity was observed at all doses of the IL-2-mediated costimulus. A reduced costimulatory activity noted at the 


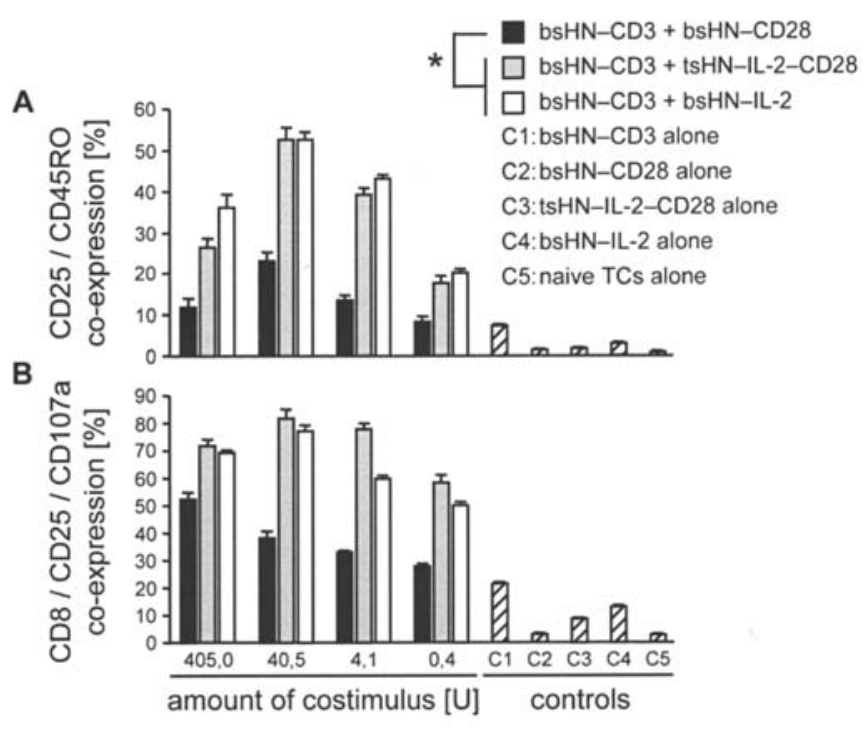

C

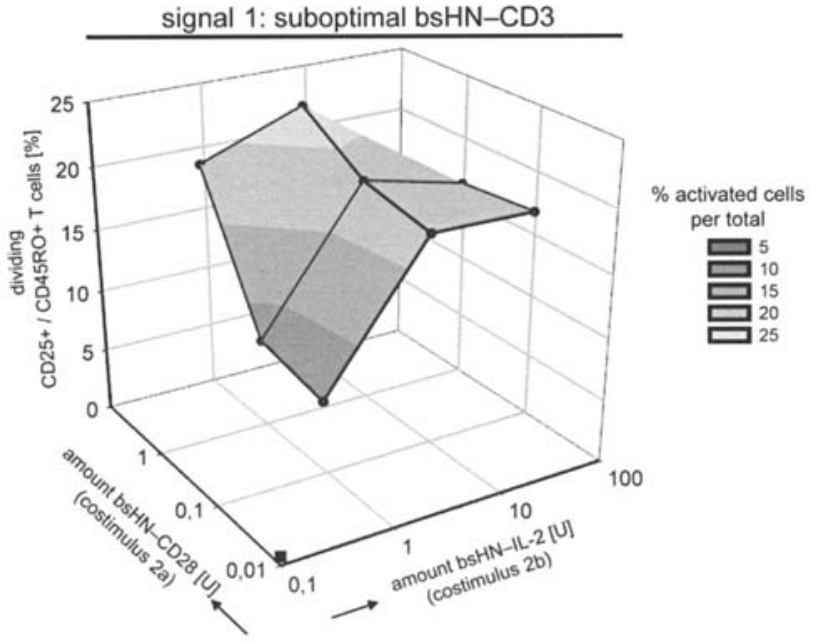

Figure 3. Optimization of naïve T cell costimulation. (A and B) Upregulation of activation markers. Purified naïve T cells (TCs) were stimulated by $\gamma$-irradiated Ltk.HN vaccine cells in the presence of a combination of a suboptimal dose of signal 1 (50 pg of bsHN-CD3) and decreasing amounts (in U/well) of each of the following fusion proteins: bsHN-CD28 (black bars), tsHN-IL-2-CD28 (gray bars) and bsHN-IL-2 (white bars). For controls ( $\mathrm{C} 1$ through $\mathrm{C} 5$; hatched bars), naïve $\mathrm{T}$ cells were incubated with Ltk.HN vaccine cells in the presence of a maximal concentration of either construct alone, or without any construct. After 6 days of incubation, cells were harvested, blocked with human $\operatorname{IgG}(50 \mathrm{mg} / \mathrm{ml})$ and stained with fluorescence-labeled mAbs. The percentages of CD25/CD45RO coexpressing T cells (A) and of CD25/CD107a co-expressing CD8 ${ }^{+} \mathrm{T}$ cells (B) are shown. Propidium iodide $(0.5 \mu \mathrm{g} / \mathrm{ml})$ was added to exclude dead cells; ${ }^{*} \mathrm{p}<0.0001$. (C) Anti-CD28- and IL-2-mediated costimuli have additive effects. Purified and CFSE-labelled naïve T cells were stimulated by MCF-7NDV vaccine cells in the presence of a suboptimal dose of signal 1 (500 pg of bsHN-CD3). For the costimulatory signals (signals 2), different combinations of the fusion proteins bsHN-CD28 (costimulus $2 \mathrm{a}$; concentrations: $0.08,0.84$ and $8.44 \mathrm{U}$ ) and bsHN-IL-2 (costimulus 2b; concentrations: $0.84,8.44$ and $84.4 \mathrm{U}$ ) were added. After 6 days of incubation, the $\mathrm{T}$ cells were treated as described above, and the percentage of activated, i.e. dividing $\left(\mathrm{CFSE}^{\text {low}}\right.$ ) and $\mathrm{CD} 25 / \mathrm{CD} 45 \mathrm{RO}$ co-expressing $\mathrm{T}$ cells was determined by FACS analysis. The percentage (shown on the $\mathrm{z}$-axis) is represented by the gray scales in the mesh plot and increases from dark to light gray. The black square represents the suboptimal activation by bsHNCD3 alone (without costimulation). Maximal concentrations of either costimulus $2 \mathrm{a}$ or costimulus $2 \mathrm{~b}$ alone, or a combination of both on top of MCF-7-NDV vaccine cells (without signal 1) did not lead to a significant naïve $\mathrm{T}$ cell activation (data not shown). highest concentration was possibly due to competition with the bsHN-CD3 reagent that provided signal 1.

Furthermore, to determine whether the IL-2 immunocytokine-modified vaccine could also activate effector functions in naïve $\mathrm{T}$ cells, we tested by FACS analysis the upregulation of CD107a, a lysosomal associated membrane protein (LAMP-1) which becomes expressed at the outside of the plasma membrane when $\mathrm{CD}^{+} \mathrm{T}$ cells exert cytotoxic function (29). Fig. 3B shows a dose-dependent upregulation of $\mathrm{CD} 107 \mathrm{a}$ on activated $\mathrm{CD}^{+} \mathrm{T}$ cells $(\mathrm{CD} 8 / \mathrm{CD} 25$ doublepositive cells). At the optimal amount of costimulus (40.5 U), only $\sim 40 \%$ of the cells having received the anti-CD28 costimulus became cytotoxic while $\sim 80 \%$ were cytotoxic after costimulation with the new IL-2 immunocytokines.

Since all experiments so far had been performed with stable transfectants, we had to ensure that the results could be transferred to a virus-infected tumor vaccine. To this end, and also to investigate a possible relationship between the costimulatory signals $2 \mathrm{a}$ and $2 \mathrm{~b}$, we labelled purified naïve $\mathrm{T}$ cells with CFSE and coincubated them with an MCF-7-NDV tumor vaccine for 6 days. All experimental groups received a suboptimal amount of bsHN-CD3 along with three different doses of bsHN-CD28 and bsHN-IL-2 in all possible combinations. T cell activation was assessed via FACS analysis and was expressed as the percentage of dividing CD25/CD45RO double positive cells (Fig. 3C). There was a plateau of $20-25 \%$ activated cells as long as one of the two costimuli was added in a sufficient amount. Thus, a low dose of one costimulus could be compensated by a higher dose of the second one. This suggests a possible cross-talk between costimulatory signals mediated via IL-2 receptor and CD28.

Antitumor activity induced in PBMC and PBMC subsets by $N D V$-infected tumor vaccine with optimized costimulation. The main purpose of a tumor vaccine is the activation of immune antitumor activity. To evaluate such activity in vitro, we recently established a tumor neutralization assay (TNA) which is basically a mixed lymphocyte tumor cell culture (MLTC) performed on top of an adherent tumor cell monolayer as a bystander target. Coincubation of PBMC for 5-7 days with the modified vaccine cells resulted in the generation of cytotoxic effector function and in the release of a variety of cytokines (16). The surviving tumor cells were quantified by the live cell staining reagent MTS.

Fig. 4A shows the results of such assays when performed with total PBMC or with different PBMC subsets. NDV infection of the tumor vaccine was sufficient to activate NK cells to exert bystander antitumor effects. A significant increase in tumor growth inhibition was always observed with a tumor vaccine presenting signals 1 and $2 \mathrm{a}$ in subsets containing $\mathrm{T}$ cells. Purified $\mathrm{CD}^{+}$as well as purified $\mathrm{CD} 4^{+} \mathrm{T}$ cells exerted strong bystander antitumor activity upon costimulation while this was not observed with purified NK cells.

Optimization of the costimulation using IL-2 immunocytokines can further augment the antitumor activity in PBMC (Fig. 4B). Fig. 4B shows a stepwise increase in the bystander tumor growth inhibition upon tumor vaccine modification. The first effect is due to NDV infection (NDV effect). The second effect is due to the vaccine-bound costimulatory IL-2 (IL-2 effect). Finally, a combination of 
A
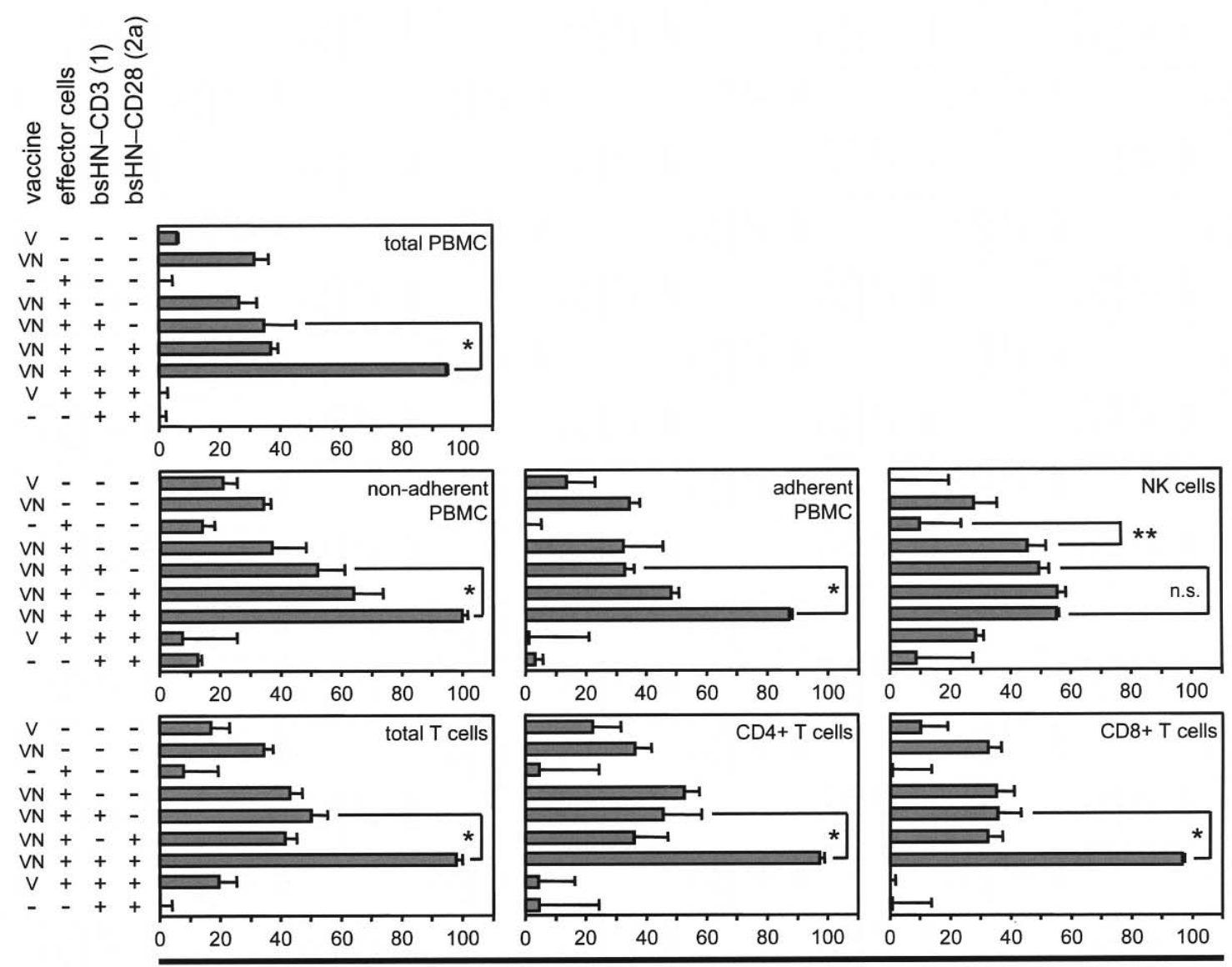

tumor growth inhibition [\%]

\section{B}

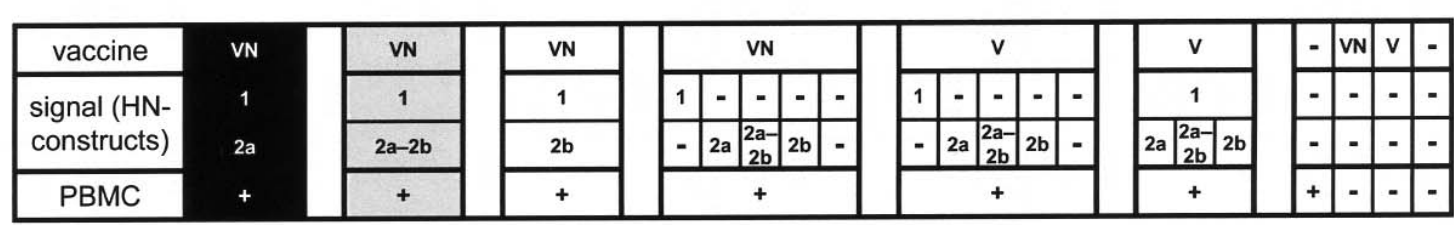

anti-CD28 + IL-2 effect

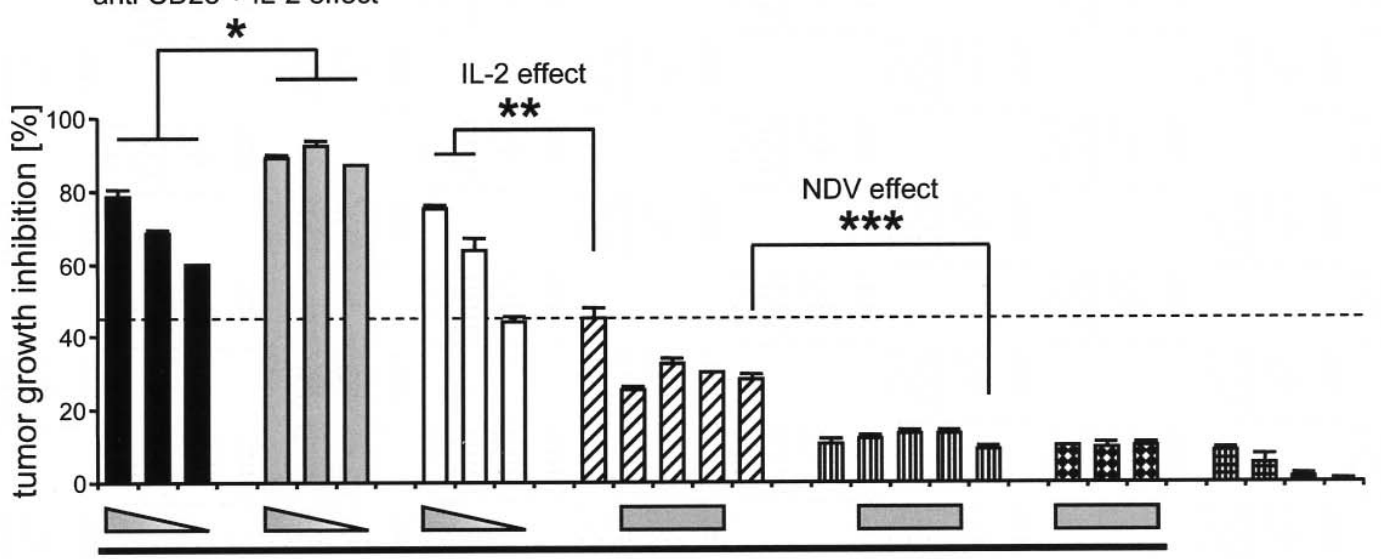

amount of costimulus [U]

Figure 4. Induction of antitumor activity in vitro. (A) Activation of bystander antitumor activity in total PBMC and PBMC subsets. For the TNA, live MCF-7 cells were seeded in 96-well plates. Cocultivated total PBMC or different PBMC subsets were activated by the indicated combinations of MCF-7 vaccine cells (V, non-infected $\gamma$-irradiated cells; VN, NDV-infected $\gamma$-irradiated cells), a suboptimal dose of bsHN-CD3 and bsHN-CD28. The bystander kill capacity was assessed by quantifying the remaining live MCF-7 cells as described in Materials and methods. The mean tumor growth inhibition of triplicate cultures \pm SD is shown. ${ }^{*} \mathrm{p}<0.02 ;{ }^{* *} \mathrm{p}<0.03$. n.s., not significantly different. (B) PBMC activated by a combination of anti-CD3, anti-CD28 and IL-2 show the strongest bystander antitumor activity. Live adherent MCF-7 monolayers were coincubated with the indicated combinations of MCF-7 vaccine cells (V, non-infected $\gamma$-irradiated cells; VN, NDV-infected $\gamma$-irradiated cells), PBMC as effector cells, a suboptimal dose of signal 1 (500 pg of bsHN-CD3) and one of the costimulatory fusion proteins bsHN-CD28 (signal 2a), tsHN-IL-2-CD28 (signal 2a-2b) or bsHN-IL-2 (signal 2b) in decreasing concentrations, ranging from 200 to $2 \mathrm{U}$ (represented by the gray triangles; gray boxes, costimulus at its maximal concentration). After 7 days, the TNA was developed as in Fig. 4A. The mean tumor growth inhibition of triplicate cultures $\pm \mathrm{SD}$ is shown. ${ }^{*} \mathrm{p}<0.005 ;{ }^{* *} \mathrm{p}<0.008 ;{ }^{* * *} \mathrm{p}<0.0001$. 
A

\begin{tabular}{|c|c|c|c|c|c|c|c|c|}
\hline vaccine & VN & VN & VN & \multicolumn{4}{|c|}{ VN } & \multirow{4}{*}{$\begin{array}{l}\text { MLTC } \\
\text { combinations }\end{array}$} \\
\hline signal (HN- & 1 & 1 & 1 & 1 & - & -5. & & \\
\hline constructs) & $2 a$ & $2 a-2 b$ & $2 b$ & - & $2 a^{2}$ & 2 & & \\
\hline naïve $T$ cells & + & + & + & & & + & & \\
\hline
\end{tabular}

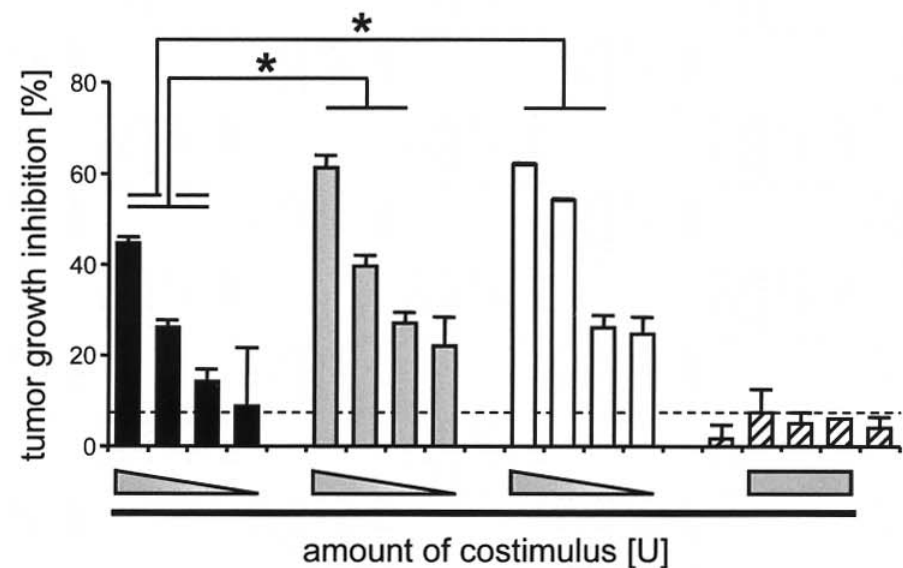

TNA

result

B

\begin{tabular}{|c|c|c|c|c|}
\hline vaccine & VN & VN & VN & VN \\
\hline signal $(\mathrm{HN}-$ & 1 & 1 & 1 & 1 \\
\hline constructs) & $2 a$ & $2 a-2 b$ & $2 b$ & - \\
\hline $\mathrm{T}$ cells & + & + & + & + \\
\hline
\end{tabular}

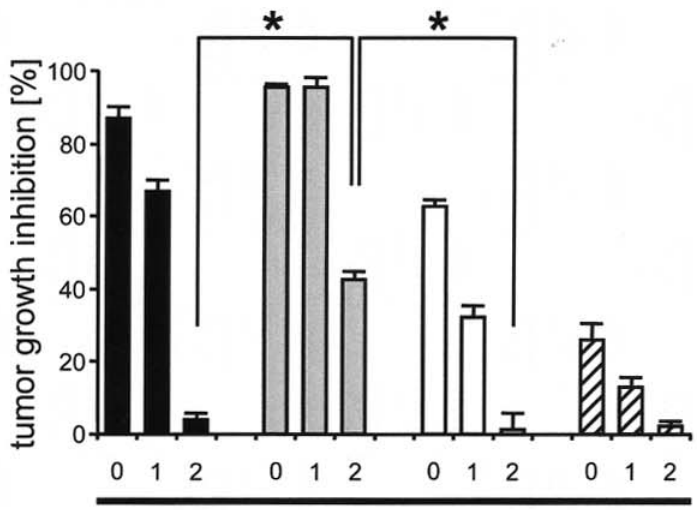

passage number

Figure 5. T cell antitumor effector phase and its duration. (A) T cells preactivated with a combination of anti-CD3, anti-CD28 and IL-2 show the strongest antitumor activity upon transfer to tumor cell monolayers. Purified naïve T cells were activated under the same conditions as described in Fig. 2A and B (MLTC combinations). After 6 days, the cells were harvested, washed and transferred onto fresh adherent MCF-7 monolayers for another 3 days of incubation (TNA result). The mean tumor growth inhibition of triplicate cultures \pm SD is shown; ${ }^{*} \mathrm{p}<0.01$. (B) T cells activated by a combination of anti-CD3, anti-CD28 and IL-2 show the most durable antitumor activity upon repeated transfer to tumor cell monolayers. In 96-well plates (TNA test plates), live adherent MCF-7 monolayers were coincubated with MCF-7-NDV vaccine cells (VN), purified T cells, a suboptimal dose of bsHN-CD3 (1 $\mu \mathrm{g}$ per $10^{7}$ vaccine cells; signal 1 ), and one of the following costimulatory fusion proteins: bsHN-CD28 (black bars; signal 2a), tsHN-IL-2-CD28 (gray bars; signal 2a-2b) and bsHN-IL-2 (white bars; signal 2b), each at a concentration of $84 \mathrm{U}$ per $10^{7}$ vaccine cells (passage 0 ). Hatched bars indicate $\mathrm{T}$ cells activated in the presence of suboptimal bsHNCD3 alone (negative controls). For serial passages, the same conditions were performed in parallel using a 6-well TNA format with identical protein concentrations (TNA passage plates). After 7 days, the TNA test plates were developed as described in Materials and methods. The cells from the TNA passage plates were harvested, washed and transferred for another 3 days onto fresh MCF-7 monolayers, either in 96-well TNA test plates (passage 1), or in 6well TNA passage plates for another round (passage 2). The mean growth inhibition of triplicate cultures \pm SD is shown; ${ }^{*} \mathrm{p}<0.0021$.

IL-2- and anti-CD28-mediated signals (anti-CD28 + IL-2 effect) resulted in the strongest antitumor activity. Notably, in the absence of NDV infection, the fusion proteins did not augment the antitumor effect even when used at optimal concentrations.
Antitumor effector activity of $T$ cells activated by NDVinfected tumor vaccine with optimized costimulation and its duration after serial passage. Since the TNA assay (Fig. 4B) does not allow for distinguishing between the steps of $\mathrm{T}$ cell activation and effector function, we next analyzed the 


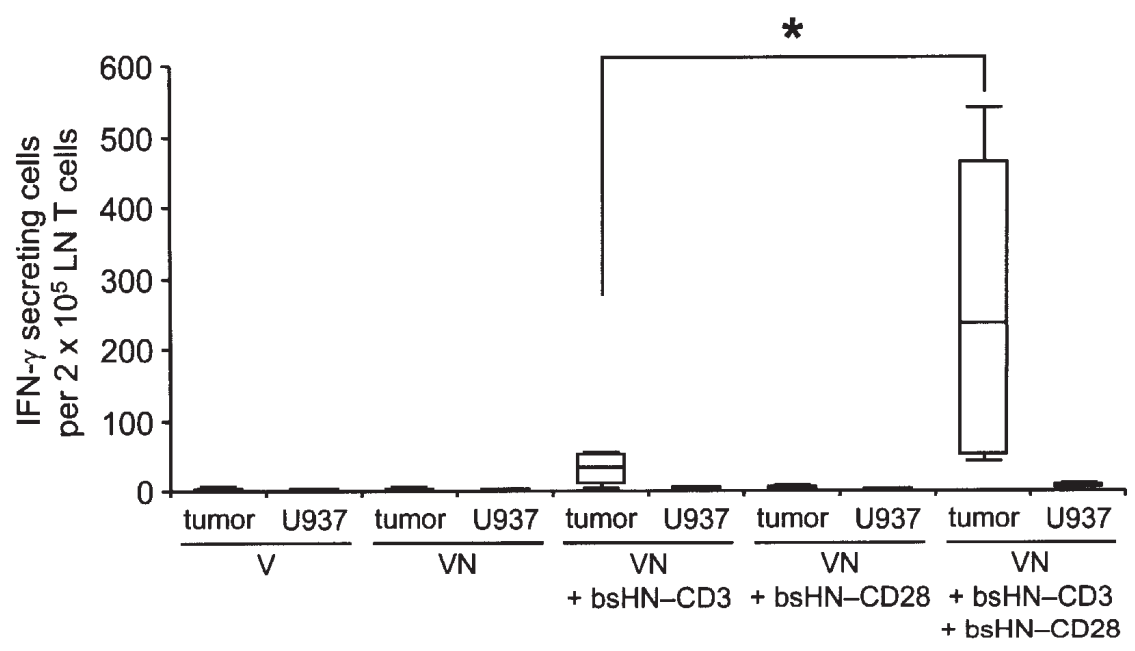

Figure 6. Memory T cells of HNSCC patients can be specifically reactivated by a modified autologous tumor cell vaccine. In a short-term IFN- $\gamma$ ELISpot assay, purified T cells isolated from draining lymph nodes (LN) of HNSCC patients were coincubated with the indicated autologous vaccine formulations (tumor) ( $\mathrm{n}=4)$. For specificity control, the irrelevant human promonocytic cell line U937 (U937) was used to activate patient T cells. The frequency of IFN- $\gamma-$ secreting $\mathrm{T}$ cells was determined as described in Materials and methods. Each boxplot column represents the pooled median, $25 \%$ and $75 \%$ (bars $5 \%$ and 95\%) quartile counts of IFN- $\gamma$-secreting T cells from the four different patients. V, non-infected $\gamma$-irradiated tumor vaccine; VN, NDV-infected $\gamma$-irradiated tumor vaccine. ${ }^{*} \mathrm{p}<0.005$.

generated effector function separately. MLTCs were first carried out for 6 days with naïve $T$ cells in the absence of tumor monolayers, using $\gamma$-irradiated Ltk.HN vaccine cells and the indicated $\mathrm{HN}$-specific fusion proteins (Fig. 5A: MLTC combinations). Upon transfer onto MCF-7 human breast carcinoma cells, within 3 days the generated effector $\mathrm{T}$ cells exerted the indicated tumor growth inhibition (Fig. 5A; TNA result). There was a significantly higher antitumor effector activity in cultures in which the costimulus was provided by IL- 2 or by IL- 2 plus anti-CD28 in comparison to anti-CD28 alone. This further supports and extends our previous results and conclusions. Another important aspect of $\mathrm{T}$ cell effector activity relates to its duration. To test this, we repeatedly transferred purified $\mathrm{T}$ cells that were activated only once by MLTC onto fresh tumor monolayers and followed destruction of the latter as shown in Fig. 5B. The results revealed a much longer duration of bystander antitumor activity in $\mathrm{T}$ cells activated by the signals $1,2 \mathrm{a}$ and 2b together (bsHN-CD3 plus tsHN-IL-2-CD28) than in T cells activated by only two signals. Expressed quantitatively, a simultaneous introduction of costimulatory signals via CD28 (signal 2a) and IL-2 receptor (signal 2b) led to a 20$40 \%$ increased bystander antitumor activity in passage 1 (days 7-10) and passage 2 (days 10-13) when compared to a tumor vaccine with only one costimulatory signal.

Reactivation of memory $T$ cells from cancer patients by $N D V$-infected autologous tumor vaccine loaded with bsHN$C D 3$ and bsHN-CD28. All experiments so far were performed with immune cells from normal healthy donors. Therefore, it was important to test if the modified vaccine would also be capable of (re)activating $\mathrm{T}$ cells from cancer patients. For that purpose, we applied a modified short-term IFN- $\gamma$ ELISpot assay which we previously established for reactivation of cancer-reactive memory $\mathrm{T}$ cells (28). From four different tumor patients, operated on for HNSCC, primary tumor cells were expanded, were prepared as a vaccine (NDV infection and loading with the fusion proteins) and were finally combined with autologous $\mathrm{T}$ cells isolated from draining lymph nodes. The data from Fig. 6 show a strong IFN- $\gamma$ secretion only in that group where T cells received both anti-CD3 and anti-CD28 signals. Specificity was demonstrated by using the human promonocytic lymphoma cell line U937 which could not (re)activate T cells under the same conditions.

In vivo therapeutic efficiency of human PBMC preactivated in vitro by $N D V$-infected tumor vaccine loaded with bsHN$C D 3$ and $b s H N-C D 28$. To study the immunotherapeutic effects of vaccine-activated PBMC in vivo, we recently established an NOD/SCID mouse model which allows outgrowth of the MCF-7 breast cancer cell line (28). For therapy, PBMC from a healthy donor were preactivated with an MCF-7-NDV tumor vaccine (VN) loaded or not with bsHN-CD3 and bsHN-CD28, followed by i.p. injections into mice with established MCF-7 xenotransplants (Fig. 7A). PBS-treated control mice showed progressive tumor growth, as did tumors from mice treated with PBMC preactivated with MCF-7NDV tumor vaccine only. The tumors of mice, however, treated with fully activated PBMC started to regress 51 days after adoptive cell transfer. Notably, treatment of mice with supernatants from fully activated PBMC cultures, did not lead to tumor regression. Immunohistochemical stainings of tumors that underwent regression revealed a heavy infiltration by both human $\mathrm{CD}^{+}$and $\mathrm{CD} 8^{+} \mathrm{T}$ cells, a certain percentage of which were activated (CD69 positive) and exhibited a memory phenotype (CD45RO positive). In contrast, tumor sections from PBS-treated controls revealed no tumorinfiltrating T cells (Fig. 7B).

\section{Discussion}

We demonstrated here strong potentiation of $\mathrm{T}$ cell antitumor activity by the use of $\mathrm{T}$ cell-activating bispecific and trispecific fusion proteins and IL-2 immunocytokines which 
A

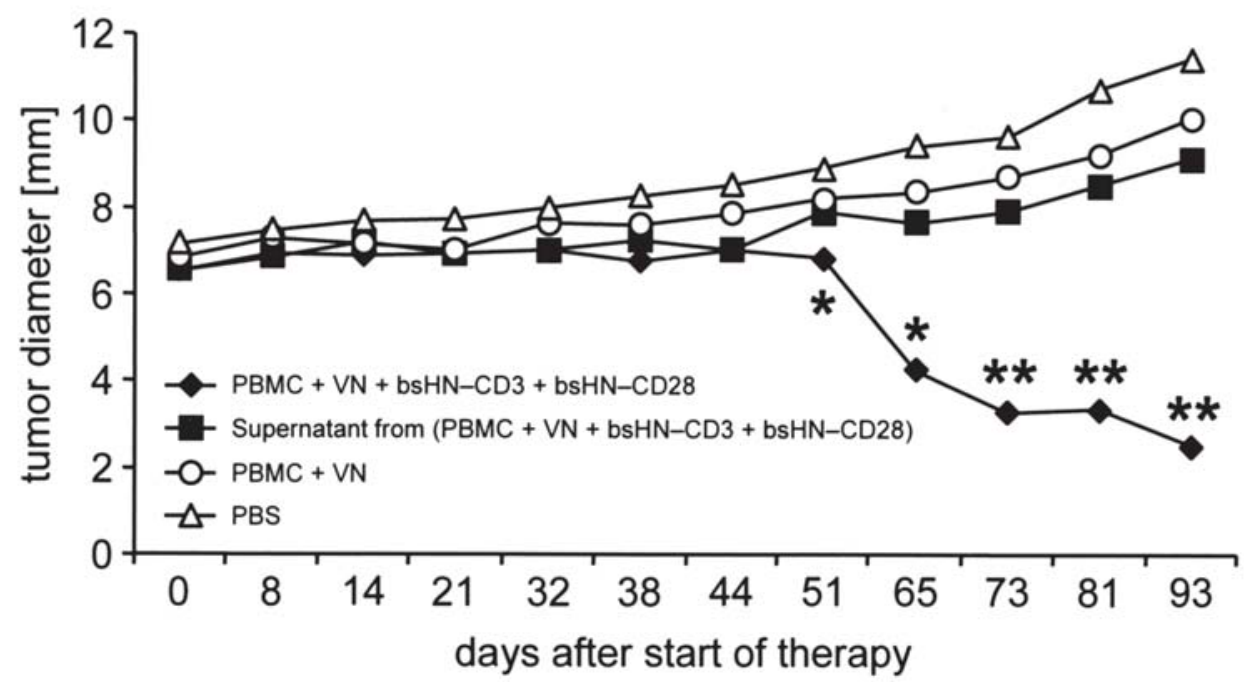

B

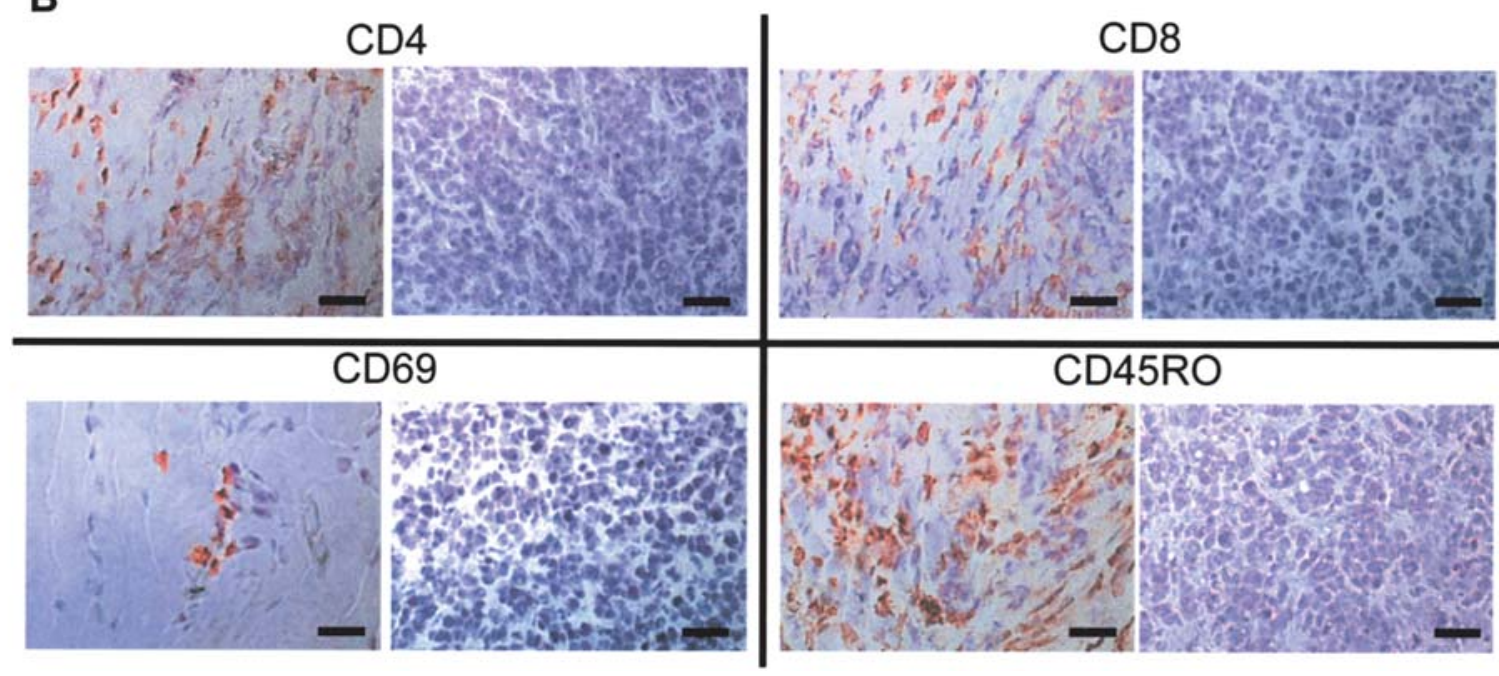

Figure 7. PBMC preactivated by MCF-7-NDV vaccine loaded with bsHN-CD3 and bsHN-CD28 can cause tumor regression upon adoptive transfer to human tumor xenotransplanted mice. (A) Tumor growth curves. MCF-7 tumor cells were s.c. injected into NOD/SCID mice (n=8 per group). The mice were kept until palpable tumors were established (6-8 $\mathrm{mm}$ in diameter). Then, at days 1,4 , and 7 the mice were treated by i.p. injection of $10^{7} \mathrm{PBMC}$ which were preactivated ex vivo for 3 days under the indicated conditions. Tumor growth was monitored over time. VN, NDV-infected $\gamma$-irradiated MCF-7 tumor vaccine. ${ }^{*} \mathrm{p}<0.05$. ${ }^{* *} \mathrm{p}<0.005$. (B) Representative immunohistochemistry images of tumor tissue sections in PBS-treated control mice (right-hand images) and in mice treated with PBMC preactivated with MCF-7-NDV, bsHN-CD3 and bsHN-CD28 (left-hand images). The sections were stained with mAbs against the human antigens CD4, CD8, CD69 and CD45RO, respectively. Scale bar, $100 \mu \mathrm{m}$.

were attached to an NDV-infected human tumor vaccine. The extent of the $\mathrm{T}$ cell-mediated tumor growth suppression particularly depended on the optimization of the costimulatory signals (anti-CD28 and IL-2). We furthermore demonstrated that human effector $\mathrm{T}$ cells, which were preactivated by such a modified tumor vaccine, could be induced for in vivo antitumor activity against established tumors.

Since many tumors lack appropriate costimulatory ligands for $\mathrm{T}$ cell activation (5), numerous studies have aimed at introducing costimulatory molecules into tumor cells via gene transfer, including the CD28 ligands CD80 (B7-1) and CD86 (B7-2). Using established tumor cell lines which were modified by electroporation $(30,31)$ or by recombinant viral vector transfection (32-34) to express the costimulatory molecules, this strategy often resulted in impressive tumor regression rates and antitumor immunity in various murine tumor models. A clinical application of this approach, however, is generally impeded by technical hurdles and low transfection efficiencies. For instance, in one study, from 116 malignant gliomas only three patients could be vaccinated by a retrovirally transduced autologous tumor vaccine (35). For comparison, in our glioblastoma study, the efficiency of ATV-NDV production was $90 \%$ (26), which underlines the feasibility and reproducibility of our autologous tumor vaccine preparation. Furthermore, we showed previously $(15,16)$, and confirmed here, that all of our bispecific and trispecific fusion proteins/immunocytokines do not trigger $\mathrm{T}$ cells by themselves, but only when attached to HN-expressing transfectants or NDV-infected tumor vaccine cells, thus demonstrating specificity and safety. Instead of introducing the CD28 ligands CD80 or CD86 into the tumor vaccine, we preferred the use of antiCD28 scFv binding sites, since in contrast to CD80 and CD86 the latter bind to costimulatory CD28, but not to coinhibitory cytotoxic T lymphocyte antigen-4 (CTLA-4) 
molecules on T cells (36). Therefore, it can be assumed that concomitant administration of CTLA-4 blocking reagents to augment $\mathrm{T}$ cell-mediated antitumor immunity (37-39) would not be necessary.

The present study for the first time introduces $\mathrm{HN}$-specific IL-2 immunocytokines, recombinant antibody-cytokine fusion proteins, which can target tumors and achieve high cytokine concentrations in the tumor microenvironment. We chose the cytokine IL-2 because IL-2 immunocytokines were shown, in syngeneic mouse tumor models, to be capable of eradicating established pulmonary and hepatic metastases of melanoma (40) and colon carcinoma (41). Our study reveals that in the presence of a TCR/CD3-mediated signal 1, the vaccine-bound IL-2 immunocytokine bsHN-IL-2 provided a $\mathrm{T}$ cell costimulatory signal which led to the induction of naïve $\mathrm{T}$ cell proliferation, upregulation of activation and memory markers and generation of antitumor cytotoxic effector cells. Since in the absence of signal 1, bsHN-IL-2 alone did not induce (de novo naïve) $\mathrm{T}$ cell activation, tumor vaccine-bound IL-2 can be considered as a costimulus, similar to anti-CD28. To the best of our knowledge, this fact has not been previously described. Further investigations of anti-CD28- and IL-2 receptor-mediated costimulation during naïve $\mathrm{T}$ cell activation are in progress. Most important was the finding that a single human $\mathrm{T}$ cell stimulation with a vaccine providing signal 1 and costimulatory signals via CD28 and IL-2 receptor induced the strongest (Fig. 4B) and most durable (Fig. 5B) antitumor effect. Without the IL-2-mediated signal the duration of this bystander antitumor activity was much shorter. These findings are in accord with recent data demonstrating that IL-2 signals during priming endow $\mathrm{CD}^{+} \mathrm{T}$ cells with a memory program of secondary expansion capacity (42). Additionally, they corroborate results from other groups who provide evidence that a combination of two [anti-CD28/anti4-1BB (43)] or even three [B7-1/ICAM-1/LFA-3 (44)] costimuli synergize and induce $\mathrm{T}$ cell activation to a far greater extent than any one of the costimulatory molecule(s) alone.

In this study, using NOD/SCID mice xenotransplanted with the human breast carcinoma cell line MCF-7, we also demonstrated for the first time the in vivo antitumor activity of human effector T cells activated by NDV-infected MCF-7 tumor vaccine cells and optimized anti-CD3/anti-CD28 signals (fully activated PBMC). That only the tumors from mice treated with the fully activated PBMC eventually regressed and became heavily infiltrated by $\mathrm{T}$ cells points at a cellular, rather than humoral immune response in which both $\mathrm{CD}^{+}$and $\mathrm{CD}^{+} \mathrm{T}$ cells seem to be involved $(45,46)$. This observation is supported by two facts. First, neither tumors of mice treated with tumor vaccine-activated PBMC, nor tumors of mice treated with supernatants from fully activated PBMC exhibited tumor regression. Second, tumor-infiltrating cells from both $\mathrm{T}$ cell subsets showed strong expression of the activation marker CD69 and the memory marker CD45RO, reflecting our in vitro data. It is noteworthy that we used polyclonally (anti-CD3/anti-CD28) activated T cells (as a PBMC subset) from a healthy donor. These did not contain a strongly enriched fraction of TAA-specific T cells, as used by others for adoptive immunotherapy (47-49). Nevertheless, in spite of the xenograft human-into-mouse transfer system, we observed a therapeutic effect but no signs of graft-versus- host disease (GvHD) (data not shown). This is in line with our previous in vitro observations where we revealed a remarkable selectivity of such polyclonally activated $\mathrm{T}$ cells for tumor verus non-tumor cell lines (16). The reason for this selectivity is still unclear. It may have to do with the fact that the $\mathrm{T}$ cells were activated with anti-CD3/anti-CD28 signals in the presence of tumor vaccine cells and danger signals.

Such an assumption is supported by our ELISpot results. The activation of naïve $\mathrm{T}$ cells by the modified vaccine required 5-7 days. In contrast, activation of memory T cells is known to be shorter (50). Using a short-term memory assay, we were able to stimulate a significant immune response in patient-derived $\mathrm{T}$ cells coincubated with an autologous, NDV-infected tumor vaccine optimized with anti-CD3/antiCD28 signals. This finding points towards an induction of a specific memory $\mathrm{T}$ cell response, since i) our short-term assay $(\sim 48 \mathrm{~h})$ detects memory, rather than de novo naïve $\mathrm{T}$ cell activation (28), and ii) an unrelated tumor cell line, U937, lacking TAA from HNSCC, did not provoke any significant $\mathrm{T}$ cell response upon similar modification. We verified that U937 cells could indeed be infected efficiently by NDV and could be modified by both bsHN-CD3 and bsHN-CD28 (data not shown). We therefore propose that the specific short-term ELISpot response required recognition of TAA from HNSCC patients and amplification by $\mathrm{T}$ cellactivating signals 1 and $2 \mathrm{a}$.

In order to improve the efficacy of immunotherapeutical approaches, there is a need to maximize the antitumor response, including the attack of tumor escape variants that lack the ability to present a given TAA. The promising results obtained here with our second generation tumor vaccine demonstrate that it has a dual activity: it can activate specific $\mathrm{T}$ cells from cancer patients (most likely TAA-specific memory $\mathrm{T}$ cells) and can generate antitumor activity from naïve $\mathrm{T}$ cells. This dual activity is particularly vital for patients whose $\mathrm{T}$ cells exhibit a high degree of unresponsiveness to stimulation via TAA. Also, in comparison to genetically modified tumor vaccines, our modular approach of attachment of fusion proteins and/or IL-2 immunocytokines has the advantage of easy qualitative and quantitative adjustment of the $\mathrm{T}$ cell-activating signals to the requirements of the patient. Finally, a clinical phase I/II trial using autologous tumor vaccine cells (ATV-NDV) modified by the fusion proteins bsHN-CD3 and bsHN-CD28 has recently been initiated, in order to validate our findings in colorectal cancer patients.

\section{Acknowledgements}

We thank A. Arnold for the help with the purification of the various fusion proteins. The generation of bispecific reagents was supported by the Dietmar Hopp Foundation, Walldorf, Germany (1998-2001).

\section{References}

1. Viola A and Lanzavecchia A: T cell activation determined by $\mathrm{T}$ cell receptor number and tunable thresholds. Science 273: 104-106, 1996.

2. Wulfing C, Rabinowitz JD, Beeson C, Sjaastad MD, McConnell HM and Davis MM: Kinetics and extent of $\mathrm{T}$ cell activation as measured with the calcium signal. J Exp Med 185: 1815-1825, 1997. 
3. Viola A, Schroeder S, Sakakibara Y and Lanzavecchia A: $\mathrm{T}$ lymphocyte costimulation mediated by reorganization of membrane microdomains. Science 283: 680-682, 1999.

4. Tuosto L and Acuto O: CD28 affects the earliest signaling events generated by TCR engagement. Eur J Immunol 28: 2131-2142, 1998.

5. Sharpe AH and Freeman GJ: The B7-CD28 superfamily. Nat Rev Immunol 2: 116-126, 2002.

6. Acuto O and Michel F: CD28-mediated co-stimulation: a quantitative support for TCR signalling. Nat Rev Immunol 3: 939-951, 2003

7. Iezzi G, Karjalainen $\mathrm{K}$ and Lanzavecchia A: The duration of antigenic stimulation determines the fate of naive and effector T cells. Immunity 8: 89-95, 1998.

8. Iezzi G, Scotet E, Scheidegger D and Lanzavecchia A: The interplay between the duration of TCR and cytokine signaling determines T cell polarization. Eur J Immunol 29: 4092-4101, 1999.

9. Schwartz RH: T cell anergy. Annu Rev Immunol 21: 305-334, 2003.

10. Wells AD, Li XC, Li Y, Walsh MC, Zheng XX, Wu Z, Nunez G, Tang A, Sayegh M, Hancock WW, Strom TB and Turka LA: Requirement for T-cell apoptosis in the induction of peripheral transplantation tolerance. Nat Med 5: 1303-1307, 1999.

11. Boise LH, Minn AJ, Noel PJ, June CH, Accavitti MA, Lindsten T and Thompson CB: CD28 costimulation can promote $\mathrm{T}$ cell survival by enhancing the expression of Bcl-XL. Immunity 3 : 87-98, 1995.

12. Jenkins MK, Taylor PS, Norton SD and Urdahl KB: CD28 delivers a costimulatory signal involved in antigen-specific IL-2 production by human T cells. J Immunol 147: 2461-2466, 1991.

13. Lenschow DJ, Walunas TL and Bluestone JA: CD28/B7 system of T cell costimulation. Annu Rev Immunol 14: 233-258, 1996.

14. Zambricki E, Shigeoka A, Kishimoto H, Sprent J, Burakoff S, Carpenter C, Milford E and McKay D: Signaling T-cell survival and death by IL-2 and IL-15. Am J Transplant 5: 2623-2631, 2005.

15. Haas C, Lulei M, Fournier P, Arnold A and Schirrmacher V: T-cell triggering by CD3- and CD28-binding molecules linked to a human virus-modified tumor cell vaccine. Vaccine 23: 2439-2453, 2005.

16. Haas C, Lulei M, Fournier P, Arnold A and Schirrmacher V: A tumor vaccine containing anti-CD3 and anti-CD28 bispecific antibodies triggers strong and durable antitumor activity in human lymphocytes. Int J Cancer 118: 658-667, 2006.

17. Bian H, Fournier P, Moormann R, Peeters B and Schirrmacher V: Selective gene transfer in vitro to tumor cells via recombinant Newcastle disease virus. Cancer Gene Ther 12: 295-303, 2005.

18. Washburn B and Schirrmacher V: Human tumor cell infection by Newcastle Disease Virus leads to upregulation of HLA and cell adhesion molecules and to induction of interferons, chemokines and finally apoptosis. Int J Oncol 21: 85-93, 2002.

19. Fiola C, Peeters B, Fournier P, Arnold A, Bucur M and Schirrmacher V: Tumor selective replication of Newcastle disease virus: association with defects of tumor cells in antiviral defence. Int J Cancer 119: 328-338, 2006.

20. Schirrmacher V, Haas C, Bonifer R, Ahlert T, Gerhards R and Ertel C: Human tumor cell modification by virus infection: an efficient and safe way to produce cancer vaccine with pleiotropic immune stimulatory properties when using Newcastle disease virus. Gene Ther 6: 63-73, 1999.

21. Ahlert T, Sauerbrei W, Bastert G, Ruhland S, Bartik B, Simiantonaki N, Schumacher J, Hacker B, Schumacher M and Schirrmacher V: Tumor-cell number and viability as quality and efficacy parameters of autologous virus-modified cancer vaccines in patients with breast or ovarian cancer. J Clin Oncol 15: 1354-1366, 1997

22. Schirrmacher V: Clinical trials of antitumor vaccination with an autologous tumor cell vaccine modified by virus infection: improvement of patient survival based on improved antitumor immune memory. Cancer Immunol Immunother 54: 587-598, 2005.

23. Ockert D, Schirrmacher V, Beck N, Stoelben E, Ahlert T, Flechtenmacher J, Hagmuller E, Buchcik R, Nagel M and Saeger HD: Newcastle disease virus-infected intact autologous tumor cell vaccine for adjuvant active specific immunotherapy of resected colorectal carcinoma. Clin Cancer Res 2: 21-28, 1996.

24. Schirrmacher V, Ahlert T, Probstle T, Steiner HH, Herold-Mende C, Gerhards R, Hagmuller E and Steiner HH: Immunization with virus-modified tumor cells. Semin Oncol 25: 677-696, 1998
25. Karcher J, Dyckhoff G, Beckhove P, Reisser C, Brysch M, Ziouta Y, Helmke BH, Weidauer H, Schirrmacher V and Herold-Mende C: Antitumor vaccination in patients with head and neck squamous cell carcinomas with autologous virusmodified tumor cells. Cancer Res 64: 8057-8061, 2004.

26. Steiner HH, Bonsanto MM, Beckhove P, Brysch M, Geletneky K, Ahmadi R, Schuele-Freyer R, Kremer P, Ranaie G, Matejic D, Bauer H, Kiessling M, Kunze S, Schirrmacher V and Herold-Mende C: Antitumor vaccination of patients with glioblastoma multiforme: a pilot study to assess feasibility, safety, and clinical benefit. J Clin Oncol 22: 4272-4281, 2004.

27. Ertel C, Millar NS, Emmerson PT, Schirrmacher V and von Hoegen P: Viral hemagglutinin augments peptide-specific cytotoxic T cell responses. Eur J Immunol 23: 2592-2596, 1993.

28. Feuerer M, Beckhove P, Bai L, Solomayer EF, Bastert G, Diel IJ, Pedain C, Oberniedermayr M, Schirrmacher V and Umansky V: Therapy of human tumors in NOD/SCID mice with patient-derived reactivated memory $\mathrm{T}$ cells from bone marrow. Nat Med 7: 452-458, 2001

29. Parkinson-Lawrence EJ, Dean CJ, Chang M, Hopwood JJ, Meikle PJ and Brooks DA: Immunochemical analysis of CD107a (LAMP-1). Cell Immunol 236: 161-166, 2005.

30. Ando H, Saio M, Ohe N, Tamakawa N, Yu H, Nakayama T, Yoshimura S, Kaku Y, Iwama T, Shinoda J, Sakai N and Takami T: B7.1 immunogene therapy effectively activates $\mathrm{CD}(4+)$ tumor-infiltrating lymphocytes in the central nervous system in comparison with B7.2 gene therapy. Int J Oncol 20: 807-812, 2002

31. Yang G, Hellstrom KE, Hellstrom I and Chen L: Antitumor immunity elicited by tumor cells transfected with B7-2, a second ligand for CD28/CTLA-4 costimulatory molecules. J Immunol 154: 2794-2800, 1995.

32. Hoshitani Y, Ishida H, Otsuki N, Shirakawa T, Gotoh A and Nibu K: Induction of immunological antitumor effects by adenovirus-mediated gene transfer of B 7-1 in a murine squamous cell carcinoma cell line. Arch Otolaryngol Head Neck Surg 133: 270-275, 2007.

33. Yang Y, Yang S, Ye Z, Jaffar J, Zhou Y, Cutter E, Lieber A, Hellstrom I and Hellstrom KE: Tumor cells expressing antiCD137 scFv induce a tumor-destructive environment. Cancer Res 67: 2339-2344, 2007

34. Takahashi T, Hirano N, Takahashi T, Chiba S, Yazaki Y and Hirai H: Immunogene therapy against mouse leukemia using B7 molecules. Cancer Gene Ther 7: 144-150, 2000

35. Parney IF, Chang LJ, Farr-Jones MA, Hao C, Smylie M and Petruk KC: Technical hurdles in a pilot clinical trial of combined B 7-2 and GM-CSF immunogene therapy for glioblastomas and melanomas. J Neurooncol 78: 71-80, 2006.

36. Olive D, Cerdan C, Costello R, Sielleur I, Ragueneau M, Pages F, Klasen S, Nunes J and Imbert J: CD28 and CTLA-4 cluster report. In: Leucocyte Typing V - White Cell Differentiation Antigens. Schlossman SF, Boumsell L, Gilks W, Harlan JM, Kishimoto T, Morimoto C, Ritz J, Shaw S, Silverstein R, Springer T, Tedder TF and Todd RF (eds). Vol. 1, Oxford University Press, Oxford, pp360-370, 1995.

37. Sabel MS, Hess SD, Egilmez NK, Conway TF Jr, Chen FA and Bankert RB: CTLA-4 blockade augments human T lymphocytemediated suppression of lung tumor xenografts in SCID mice. Cancer Immunol Immunother 54: 944-952, 2005.

38. Nagamori M, Kawaguchi S, Murakami M, Wada T, Nagoya S, Yamashita $\mathrm{T}$, Inobe $\mathrm{M}$ and Uede $\mathrm{T}$ : Intrinsic and extrinsic manipulation of B7/CTLA-4 interaction for induction of antitumor immunity against osteosarcoma cells. Anticancer Res 22: 3223-3227, 2002.

39. Kwon ED, Hurwitz AA, Foster BA, Madias C, Feldhaus AL, Greenberg NM, Burg MB and Allison JP: Manipulation of T cell costimulatory and inhibitory signals for immunotherapy of prostate cancer. Proc Natl Acad Sci USA 94: 8099-8103, 1997.

40. Becker JC, Pancook JD, Gillies SD, Furukawa K and Reisfeld RA: $\mathrm{T}$ cell-mediated eradication of murine metastatic melanoma induced by targeted interleukin 2 therapy. J Exp Med 183: 2361-2366, 1996 .

41. Xiang R, Lode HN, Dolman CS, Dreier T, Varki NM, Qian X, Lo KM, Lan Y, Super M, Gillies SD and Reisfeld RA: Elimination of established murine colon carcinoma metastases by antibody-interleukin 2 fusion protein therapy. Cancer Res 57: 4948-4955, 1997

42. Williams MA, Tyznik AJ and Bevan MJ: Interleukin-2 signals during priming are required for secondary expansion of $\mathrm{CD} 8^{+}$ memory T cells. Nature 441: 890-893, 2006. 
43. Kroon HM, Li Q, Teitz-Tennenbaum S, Whitfield JR, Noone AM and Chang AE: 4-1BB costimulation of effector T cells for adoptive immunotherapy of cancer: involvement of $\mathrm{Bcl}$ gene family members. J Immunother 30: 406-416, 2007.

44. Hodge JW, Sabzevari H, Yafal AG, Gritz L, Lorenz MG and Schlom J: A triad of costimulatory molecules synergize to amplify T-cell activation. Cancer Res 59: 5800-5807, 1999.

45. Hirano N, Takahashi T, Takahashi T, Azuma M, Okumura K, Yazaki Y, Yagita $\mathrm{H}$ and Hirai $\mathrm{H}$ : Protective and therapeutic immunity against leukemia induced by irradiated B7-1 (CD80)transduced leukemic cells. Hum Gene Ther 8: 1375-1384, 1997.

46. Li Y, McGowan P, Hellstrom I, Hellstrom KE and Chen L: Costimulation of tumor-reactive $\mathrm{CD}^{+}$and $\mathrm{CD} 8^{+} \mathrm{T}$ lymphocytes by $\mathrm{B} 7$, a natural ligand for $\mathrm{CD} 28$, can be used to treat established mouse melanoma. J Immunol 153: 421-428, 1994.
47. Rossig C, Pscherer S, Landmeier S, Altvater B, Jurgens H and Vormoor J: Adoptive cellular immunotherapy with CD19specific T cells. Klin Padiatr 217: 351-356, 2005.

48. Koehler H, Kofler D, Hombach A and Abken H: CD28 costimulation overcomes transforming growth factor-betamediated repression of proliferation of redirected human $\mathrm{CD}^{+}$ and $\mathrm{CD} 8^{+} \mathrm{T}$ cells in an antitumor cell attack. Cancer Res 67: 2265-2273, 2007.

49. Kowolik CM, Topp MS, Gonzalez S, Pfeiffer T, Olivares S, Gonzalez N, Smith DD, Forman SJ, Jensen MC and Cooper LJ: CD28 costimulation provided through a CD19-specific chimeric antigen receptor enhances in vivo persistence and antitumor efficacy of adoptively transferred T cells. Cancer Res 66: 10995-11004, 2006

50. Veiga-Fernandes H, Walter U, Bourgeois C, McLean A and Rocha B: Response of naive and memory CD $8^{+} \mathrm{T}$ cells to antigen stimulation in vivo. Nat Immunol 1: 47-53, 2000. 